\title{
A MATHEMATICAL APPROACH TO THE THEORY OF GLACIER SLIDING
}

\author{
By A. C. Fowler \\ (School of Mathematics, 39 Trinity College, Dublin, Republic of Ireland)
}

\begin{abstract}
Previous theories of glacier sliding are subject to the criticism that they are not properly formulated. Here we describe how the basal ice flow may be related to the bulk ice flow by means of the formal mathematical method of matched asymptotic expansions. A complete model of the basal sliding (involving coupled problems in ice, water film, and bedrock) may be rationally reduced by a dimensional analysis to a consideration of the ice flow only, and regelation may be neglected provided roughness is absent on the finest scales $(<c .1 \mathrm{~mm})$. If the viscosity is supposed to be independent of the moisture content, then complementary variational principles exist which allow bounds on the drag to be obtained. In particular, these determine the magnitude of the basal velocity in terms of two crucial dimensionless parameters. Arguments are presented as to why realistic sliding laws should be taken as continuous functions of the temperature, and a (major) consequence of this assumption is mentioned. Finally the effect of cavitation is discussed, via an (exact) leading-order solution of the ice flow in the particular case of a Newtonian fluid and a "small" bedrock slope.
\end{abstract}

RÉsumÉ. Une approche mathématique de la théorie du glissement des glaciers. Les théories précédentes du glissement des glaciers sont sujettes à la critique de n'être pas convenablement formulées. Nous décrivons ici comment l'écoulement de la glace au fond peut être relié à l'écoulement d'ensemble de la masse de glace par le moyen de la méthode mathématique formelle des développements asymptotiques équivalents. Un modèle complet du glissement au fond (comprenant les problèmes connexes sur la glace, le film liquide et le lit rocheux) peut être rationnellement réduit par une analyse dimensionnelle à une considération d'écoulement de glace uniquement, et le regel peut être négligé pourvu que la rugosité soit absente aux échelles les plus fines $(<1 \mathrm{~mm})$. Si on suppose que la viscosité est indépendante de la teneur en eau, il existe des principes complémentaires de variations qui permettent de fixer des limites au frottement. En particulier, ces principes déterminent l'ordre de grandeur de la vitesse au fond par le biais de deux paramètres adimensionnels fondamentaux. On présente des arguments expliquant pourquoi des lois réalistes de glissement doivent être considérées comme des fonctions de la température et une conséquence (essentielle) de cette hypothèse est mentionnée. L'effet de la teneur en eau liquide est brièvement évoqué et finalement celui de la cavitation est discuté à partir d'une solution théorique (exacte) de l'écoulement de la glace dans le cas particulier d'un fluide Newtonien et d'une pente "faible" du fond du lit.

Zusammenfassung. Ein mathematischer Zugang zur Gletschertheorie. Gegen frühere Theorien des Gletschergleitens wird der Einwand erhoben, sie seien nicht sachgemäss formuliert. In diesem Beitrag wird gezeigt, wie der Eisfluss am Untergrund mit Hilfe der formalen mathematischen Methode der angepassten asymptotischen Expansion zum Fluss der gesamten Eismasse in Beziehung gesetzt werden kann. Ein vollständiges Modell des Gleitens am Untergrund (einschliesslich der gekoppelten Probleme von Eis, Wasserfilm und Felsbett) lässt sich durch eine Dimensionsanalyse auf die Betrachtung des Eisflusses allein reduzieren; dabei ist die Regelation vernachlässigbar, sofern keine Rauhigkeit im kleinsten Ausmass ( $<\mathrm{I}$ mm) vorhanden ist. Nimmt man die Viskosität als unabhängig vom Feuchtigkeitsgehalt an, so bestehen zusätzliche Variationsprinzipien, die es gestatten, Scbranken für den Zugwiderstand festzustellen. Im einzelnen bestimmen diese die Grösse der Geschwindigkeit am Untergrund in Funktion zweier wesentlicher, dimensionsloser Parameter. Es werden Gründe dafür aufgeführt, warum realistische Gleitgesetze als kontinuierliche Funktionen der Temperatur formuliert werden sollten; eine (bedeutsamere) Folge dieser Annahme wird erwähnt. Die Wirkung des Feuchtigkeitsgehalts wird kurz betrachtet; schliesslich wird die Wirkung der Hohlraumbildung diskutiert, wobei eine exakte Lösung für das Fliessen des Eises im speziellen Fall einer Newton'schen Flüssigkeit und einer "geringen" Felsbettneigung herangezogen wird.

\section{INTRODUCTION}

It is well known that temperate ice can slide over underlying bedrock by means of a thin lubricating water film which is maintained there by pressure melting up-stream of protruding obstacles. Despite this, the effective shear stress at the bed is non-zero (considered on the large scale of the bulk ice flow) because there is a mean drag on the bed due to variations in pressure as the ice flows over the smaller-scale (rough) obstacles.

It is fairly clear that "the" basal velocity will be a function of "the" basal stress, and it is a prescription of this function (usually called the sliding law) that is to serve as a kinematic boundary condition for this rather novel fluid-mechanical situation in which both velocity and stress are non-zero at a fixed boundary. 
Although it is intuitively quite clear what we mean by "the" basal velocity and "the" basal stress, it is necessary when seeking to obtain the correct functional form of the sliding law to be mathematically precise in our definition of these terms. We accomplish this in Section 2 by considering the global ice flow over the rough bedrock using the method of matched asymptotic expansions in powers of a small parameter, $\sigma$, which is a measure of the asperity of the bedrock. Essentially, this means that we consider the flow to consist of two parts as in ordinary boundary-layer theory (Batchelor, I967), an "inner" part which describes the small-scale detail of the basal flow, and an "outer" part which describes the bulk flow of the ice over a smoothed bedrock, which varies on a much larger scale than the actual bedrock; this situation is depicted in Figure 1 . This formalism is essentially akin to ideas implicitly used by previous authors. However, neglect of an explicit consideration of the (crucial) parameter $\sigma$ can lead to errors in problem formulation. For example, while Nye's (1969) analysis of Newtonian flow is correct, this is only true if his roughness slope parameter $\epsilon$ (to be called $v$ in this paper) is small (as he indeed assumes): his problem is not correctly formulated if $\epsilon \approx \mathrm{I}$. On the other hand, Lliboutry (I976) makes the inaccurate statement that ice flow over a white ("dimensionless") bedrock depends only on four physical parameters: he neglects the glacier depth, which enters (as the parameter $\sigma$ ) via the process of matching the inner flow to the outer flow.

Thus it is the intention here to formulate the problem of determining the sliding law in a rational and consistent manner, and without making any implicit a priori assumptions about the magnitude of the basal velocity, roughness slope, etc.

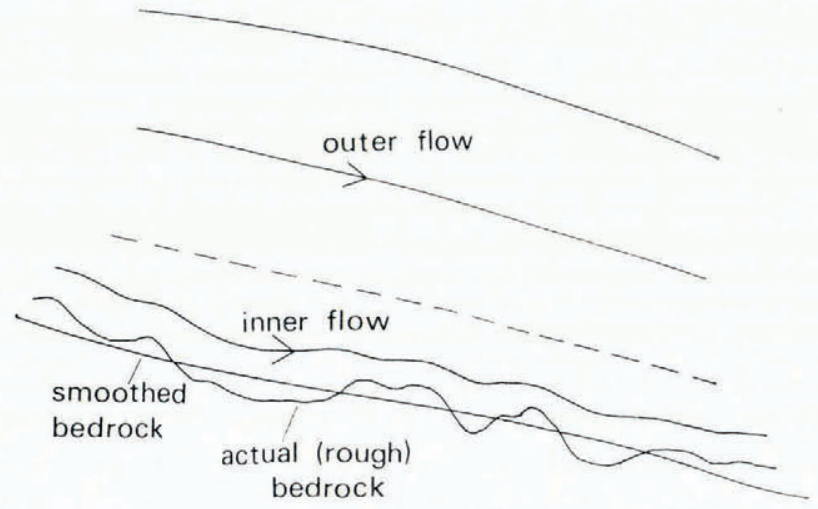

Fig. I. Diagram of inner and outer flows over a rough bedrock.

\section{Formulation, Assumptions, AND MOdel}

We assume to begin with that the ice flows two-dimensionally. The geometry of the ice flow may be essentially described by means of four different length scales. These are $l$ the length of the glacier, $d$ a typical depth, $[x]$, which is taken to be the length scale (or wavelength) of the bedrock roughness, and [y], which (in some sense) is the amplitude of the variations in bedrock roughness about a "smoothed" bedrock. We take typical values of these lengths as

$$
l \approx 10^{4} \mathrm{~m}, \quad d \approx \mathrm{IO}^{2} \mathrm{~m}, \quad[y]<[x] \approx \mathrm{I} \mathrm{m} .
$$

Between them they define three independent dimensionless parameters,

$$
\begin{gathered}
\delta=\frac{d}{l} \approx \mathrm{IO}^{-2}, \quad \sigma=\frac{[x]}{d} \approx \mathrm{IO}^{-2}, \\
\nu=\frac{[y]}{[x]}<\mathrm{I},
\end{gathered}
$$


of which the latter two are important to the sliding process, and which between them describe the degree of corrugation of the bedrock.

We now assume (as is certainly reasonable) that the actual bedrock profile may be written as the sum of a smooth and a rough component in the form

$$
d h_{\mathrm{S}}\left(\frac{x}{l}\right)+[y] h_{\mathrm{R}}\left(\frac{x}{[x]}\right)
$$

where for two-dimensional flow we take cartesian axes $(x, y)$ with the $x$-axis in the direction of the mean bedrock slope (Fowler and Larson, 1978). A decomposition such as Equation (3) could be carried out by the process of averaging described by Nye (1970) over a smoothing distance $X_{\text {av }}$ such that $[x] \ll X_{\text {av }} \ll l$. Although we have specifically taken $d$ and $l$ as the depth and length of the glacier, we only really require that $[x] \ll d, l$ for the following formalism to be valid; conversely it is clear that a decomposition like Equation (3) must always be possible if the sliding law is to have any meaning as a boundary condition for the outer flow.

Now, as described by Fowler and Larson (1978), we expect the bulk flow (away from the bedrock) to be characterized by the length and depth scales $l$ and $d$, respectively, and that this flow should be (as shown in Fig. I) "effectively" bounded by the smoothed bedrock $h_{\mathrm{S}}$. Conversely, the appropriate length scale for the inner flow problem is $[x]$, and on this scale we can effectively ignore the variation in $h_{\mathrm{S}}$ and the flow is bounded by $h_{\mathrm{R}}$, the rough bedrock. Putting this more precisely, we seek a dimensionless solution of the governing equations (for example for the velocity in the $x$-direction) in the form

$$
\left.\begin{array}{rl}
u_{\mathrm{i}} & =u_{\mathrm{i}}{ }^{(0)}\left[x_{\mathrm{i}}, y_{\mathrm{i}}\right]+\sigma u_{\mathrm{i}}{ }^{(\mathrm{r})}\left[x_{\mathrm{i}}, y_{\mathrm{i}}\right]+\ldots, \\
u_{0} & =u_{\mathrm{o}}{ }^{(0)}\left[x_{0}, y_{0}\right]+\sigma u_{\mathrm{o}}{ }^{(\mathrm{I})}\left[x_{0}, y_{0}\right]+\ldots,
\end{array}\right\}
$$

with similar expansions for the other unknowns. Here both $u_{\mathrm{i}}$ (inner) and $u_{0}$ (outer) are made dimensionless with the same velocity scale $U$ (typically $100 \mathrm{~m} \mathrm{a}^{-1}$ ), and the inner coordinates $x_{\mathrm{i}}, y_{\mathrm{i}}$ are scaled with $[x]$, whereas $x_{\mathrm{o}}$ is scaled with $l$, and $y_{0}$ is scaled with $d$.

Let us suppose both solutions are known (except for an arbitrary constant, which is to be determined by matching the two solutions together for consistency). The matching procedure, to first order, is then as follows (see, for example, Van Dyke, 1975): the matching region is to be a long way from the rough bedrock (in terms of $y_{i}$ ), but very close to the smooth bedrock (in terms of $y_{\mathrm{o}}$ ). In other words we examine the concurrent limits $y_{\mathrm{o}} \rightarrow h_{\mathrm{S}}, y_{\mathrm{i}} \rightarrow \infty$. Expanding the outer solution about the smooth boundary $h_{\mathrm{S}}$, we have

$$
u_{\mathrm{o}}=u_{\mathrm{o}}{ }^{(0)}\left[x_{\mathrm{o}}, h_{\mathrm{S}}\right]+\left(y_{\mathrm{o}}-h_{\mathrm{S}}\right) u_{\mathrm{o}} y^{(0)}\left[x_{\mathrm{o}}, h_{\mathrm{S}}\right]+\ldots+O(\sigma),
$$

which in terms of the inner variable $y_{\mathrm{i}}$, is

$$
\begin{aligned}
u_{\mathrm{o}} & =u_{\mathrm{o}}{ }^{(0)}\left[x_{\mathrm{o}}, h_{\mathrm{S}}\right]+\sigma y_{\mathrm{i}} u_{\mathrm{o} y^{(0)}}\left[x_{\mathrm{o}}, h_{\mathrm{s}}\right]+O(\sigma) \\
& =u_{\mathrm{o}}{ }^{(0)}\left[x_{\mathrm{o}}, h_{\mathrm{s}}\right]+O(\sigma) .
\end{aligned}
$$

In order that the inner solution match to this solution (to first order) we therefore require that

$$
u_{\mathrm{i}}{ }^{(0)} \rightarrow u_{\mathrm{o}}{ }^{(0)}\left[x_{0}, h_{\mathrm{S}}\right] \quad \text { as } y_{\mathrm{i}} \rightarrow \infty,
$$

and this relation is formally true provided $u_{0}{ }^{(0)}=u_{\mathrm{b}}$, the dimensionless basal velocity of the outer flow, is such that $u_{\mathrm{b}} \gg O(\sigma)$; otherwise the shearing term in Equation (6) is just as important as $u_{\mathrm{b}}$. We may suppose this to be true, since cases in which $u_{\mathrm{b}} \approx \sigma \approx \mathrm{IO}^{-2}$ are of little interest dynamically.

In exactly similar fashion, we find that the dimensionless inner shear stress $\tau_{2 \mathrm{i}}$ must satisfy

$$
\tau_{2 \mathrm{i}} \rightarrow \nu \tau_{\mathrm{b}}
$$


as $y_{\mathrm{i}} \rightarrow \infty$, where $\tau_{\mathrm{b}}$ is the basal stress of the outer flow made dimensionless with a typical stress there (e.g. I bar), and the factor $\nu$ is present because the stresses must be higher by an amount $\mathrm{I} / v$ in the inner flow in order to balance the applied stress $\tau_{\mathrm{b}}$ (Fowler, unpublished). This factor is introduced here so that we may later consider the limit $v \rightarrow 0$ : however it should be emphasized that this parametric limit is not essential to the analysis, and is used later when convenient for illustrative purposes.

These two conditions together define in a meaningful sense what the basal stress and velocity are, and show how the sliding law is determined, since, when we further prescribe the condition

$$
v_{\mathrm{i}} \rightarrow 0 \quad \text { as } y_{\mathrm{i}} \rightarrow \infty,
$$

there is an extra kinematic condition at infinity which determines a functional relation of the form

$$
u_{\mathrm{b}}=F\left(\tau_{\mathrm{b}}\right),
$$

for the inner flow problem to be solvable.

We have treated this question of formulation at some length, since it has to a certain extent been skated over in the past. We will not dwell so long on the actual model to be considered, since the appropriate equations are well known, and have been analysed elsewhere (Fowler, unpublished).

The main physical assumption we make is that the constitutive relation between the strain-rate tensor $e_{i j}$ and the deviatoric stress tensor $\tau_{i j}$ be describable by a power law of Glen's type, that is

$$
e_{i j}=A \tau^{n-1} \tau_{i j}
$$

in which $n \approx 3$ (Lliboutry, 1976), but also more importantly $A$ is assumed to be independent of the moisture content of the ice. This drastic and unrealistic assumption is likely to be of some importance, particularly in view of the observed and theoretical mechanisms of water flow which are thought to operate within basal ice (e.g. Carol, 1947; Robin, 1976).

The sliding problem is fully described by a description of three regions, those of ice, water film, and rock: these are interlinked via the boundary conditions on the interfaces. A rather long-winded dimensional analysis (in preparation for publication by the present author) may be carried out, and shows that the problem may be simplified to a great extent by the neglect of various small dimensionless parameters which occur. Previously established results are reconstructed, for example that the lubrication film thickness is $c .10^{-6} \mathrm{~m}$.

On simplification, it is found that the description of the thin water layer is akin to that of a "squeeze film" in lubrication theory, and eventually it reduces to a prescription for the (dimensionless, scaled) width of the film, $\Sigma(x)$, in terms of the (dimensionless, scaled) rate of melting of ice, $V_{\mathbf{M}}(x)$ and the pressure variation, $p(x)$ : the result (Fowler, unpublished) is

$$
\left(\mathrm{I}+v^{2} h^{\prime 2}\right) \int_{x_{0}}^{x} V_{\mathbf{M}}(x) \mathrm{d} x=-\frac{1}{12} \Sigma^{3}(x) p^{\prime}(x),
$$

where $x_{0}$ is chosen so that $\Sigma\left(x_{0}\right)=0\left(\right.$ or $\left.p^{\prime}\left(x_{0}\right)=0\right)$. With the assumption that $\Sigma$ as defined by Equation (12) remain's finite, it remains to solve the ice-flow and rock-temperature problems: as noted by others (e.g. Nye, 1969), these are coupled by the dependence of the regelative velocity $V_{M}$ (normal to the ice-rock interface) on the normal temperature gradients in rock and ice, and (except when the flow is Newtonian) the solution is therefore extremely difficult. The (unknown) regelative velocity occurs in the boundary condition at the ice-rock interface as a prescribed normal velocity there, specifically

$$
v=v u h_{\mathrm{R}}{ }^{\prime}-\alpha V_{\mathbf{M}}(x),
$$


where all the variables are scaled to be $O(\mathrm{I})$, and $\alpha$ is a dimensionless parameter of the problem, related to the regelative coefficient $\Gamma$ (Lliboutry, 1976) and also to the regelative length scale $\lambda_{*}$ of Morland (1976[a]). In the present context, we find that typically (with $[y] \approx \mathrm{I} \mathrm{m}$ ), $\alpha \leqslant O\left(\mathrm{IO}^{-3}\right)$ and is therefore negligible from the point of view of the ice flow. In this case we can replace Equation (13) by

$$
v=v u h_{\mathrm{R}}{ }^{\prime} \quad \text { on } y=v h_{\mathrm{R}},
$$

that is, the normal velocity is zero, and the ice flow uncouples from the temperature problem in the rock.

There are two notes of caution that need to be drawn. If we examine the equation for $\alpha$ (Fowler, unpublished) we can alternatively write

$$
\alpha \approx \mathrm{I} \quad \text { when }[y] \approx \mathrm{IO}^{-3} \mathrm{~m}=\mathrm{I} \mathrm{mm} \text {; }
$$

that is to say, regelation becomes an important (non-negligible) process only over roughness wavelengths $\lambda_{*}<c$. I mm. This is in contrast with Morland's (1976[a]) value of $\lambda_{*} \approx 77 \mathrm{~mm}$, and is due to the non-linearity of the flow law (and a numerical factor). Thus the effect of non-linearity in the flow law is to reduce the controlling wavelength $\lambda_{*}$. Even allowing a numerical factor of ten, it still seems safe to say that regelation is only important at roughness wavelengths of less than $\mathrm{I} \mathrm{cm}$. However, if such small-scale roughness is present, then $\alpha V_{\mathbf{M}}$ could become important because of $V_{\mathbf{M}}$ becoming large. In such a case (which includes the case "of a "white" bedrock) there is little further that can be done analytically, at least for non-Newtonian flow. However, according to Kamb (1970), roughness is typically absent at wavelengths of less than $50 \mathrm{~cm}$ : on this basis, we simply put $\alpha=0$ and neglect the regelative velocity entirely.

The second point to note is that Kamb (1970) observed "massive" amounts of regelation taking place on the sole of the Blue Glacier : it is not clear whether such observations contradict the present theory, but in any case one must remember that the neglect of hydrological effects may be of profound significance in this respect.

\section{Complementary VARIATIONAl PRinciples for the iGe flow}

Let us now suppose that the rough bedrock $h_{\mathrm{R}}$ is periodic in $x$. If we denote $x$ and $y$ components by suffices I and 2 , let $\mathbf{v}=\left(v_{1}, v_{2}\right)$ be the velocity and $\sigma_{i j}$ be the stress tensor, then we can write the equations of slow, steady ice motion in the following form, where commas denote differentiation with respect to the indicated coordinate, and the summation convention is employed.

$$
\begin{aligned}
v_{i, i} & =0, \\
\sigma_{i j, j}+f_{i} & =0, \\
\sigma_{i j} & =-p \delta_{i j}+\tau_{i j} .
\end{aligned}
$$

The rate-of-deformation tensor $e_{i j}$ is defined by

$$
e_{i j}=\frac{1}{2}\left(v_{i, j}+v_{j, i}\right) \text {. }
$$

In these equations, $f_{i}$ are the components of the gravitational force in $x$ and $y$ directions, $p$ is the pressure, $\delta_{i j}$ is the Kronecker delta, and $\tau_{i j}$ is the stress deviator. We assume that there exist functions $\Gamma\left(e_{i j}\right)$ and $\hat{\Gamma}\left(\tau_{i j}\right)$ which are such that the flow law (Equation (II)) may be written in either of the forms

$$
\begin{aligned}
\tau_{i j}=\tau_{j i} & =\frac{\partial \Gamma}{\partial e_{i j}}, \\
e_{i j}=e_{j i} & =\frac{\partial \hat{\Gamma}}{\partial \tau_{i j}} .
\end{aligned}
$$

(Power-law fluids do in fact satisfy this requirement.) 
To be precise, we specify the velocity $u_{\mathrm{b}}$ at infinity, so that the boundary conditions are (to leading order in $\sigma$ )

$$
\left.\begin{array}{rl}
v_{i} \rightarrow U_{i} & \text { as } y \rightarrow \infty, \\
U_{\mathrm{I}}=u_{\mathrm{b}}, & U_{2}=0 ;
\end{array}\right\}
$$

and we also specify that all the variables are periodic with the same period as $h$. In Equations (23) and (24) (which are simply the conditions of no flow through the bedrock, and no tangential stress there), $\mathbf{n}$ is the unit normal vector away from the ice, and $\mathbf{t}$ is the unit tangent vector. We have for convenience dropped the suffix $\mathrm{R}$ from $h_{\mathrm{R}}$.

From the solution it is required to determine the basal stress $\tau_{\mathrm{b}}$, given by

$$
\tau_{12} \rightarrow \nu \tau_{\mathbf{b}}, \quad y \rightarrow \infty .
$$

We recall that $u_{\mathrm{b}}$ in Equation (22) and $\tau_{\mathrm{b}}$ in Equation (23) are the basal velocity and basal stress of the outer flow.

Note that formally, $y \rightarrow \infty$ in Equation (22) is intended to mean a matching region, in other words a region where $O(\mathrm{I}) \ll y \ll O(\mathrm{I} / \sigma)$.

We now consider variations of the functional

$$
\begin{aligned}
\mathcal{J}=\int_{V}\left[\left\{\frac{1}{2}\left(v_{i, j}+v_{j, i}\right)-e_{i j}\right\} \tau_{i j}+\Gamma-f_{i} v_{i}-p v_{i, i}\right] \mathrm{d} V- & \\
& -\int_{S_{\mathrm{b}}} \sigma_{k j} n_{k} n_{j} v_{i} n_{i} \mathrm{~d} S-\int_{S_{\infty}} \sigma_{i j} n_{j}\left(v_{i}-U_{i}\right) \mathrm{d} S,
\end{aligned}
$$

about the solution to the problem. Functionals of this type were first comprehensively studied by Johnson (196o, 196r). The volume $V$ is bounded by the bedrock $S_{\mathrm{b}}$ and a straight line $y=$ constant within the matching region, $S_{\infty}$, and also the lines $x=0$ and $x=M, M$ being the period of the bedrock. Admissibility conditions for the variations are simply that they be periodic and sufficiently differentiable for the appropriate application of Green's theorem to be valid.

In this case it is easy to show that the first variation $\delta \mathcal{f}=0$ at the solution, so the functional is stationary there. We obtain "complementary" velocity and stress principles by restricting ourselves to variations which also satisfy the "velocity" conditions in Equations (I6), (I9), (20), (22), and (23), or the "stress" conditions in Equations (I 7), (18), (2 I), and (24): for the stress principle we replace $\left[\Gamma-e_{i j} \tau_{i j}\right]$ in Equation $(26)$ by $-\hat{\Gamma}$ (the two expressions are identically equal at a solution). With these restrictions, we find that at a solution $\mathcal{F}$ is minimized by the velocity principle, and maximized by the stress principle; since 7 is easily found at the solution to be (to leading order in $\sigma$ ) simply a multiple of the drag $\tau_{\mathrm{b}}$, it follows that we may obtain upper and lower bounds for the drag from these principles. After some simplification, the bounds can be written in the form

$$
\begin{aligned}
& \tau_{\mathrm{b}} \leqslant u_{\mathrm{b}} \star_{\mathrm{I}} / n \frac{\mathrm{I}}{M} \int_{V} e^{\star(n+1) / n} \mathrm{~d} V, \\
& u_{\mathrm{b}} \star \leqslant \tau_{\mathrm{b}}^{n}, \frac{\mathrm{I}}{M} \int_{V}\left[\tau^{\star n+1}-\nu^{n+\mathrm{I}}\right] \mathrm{d} V,
\end{aligned}
$$

where

$$
u_{\mathrm{b}}=\frac{\sigma}{\nu^{n+1}} u_{\mathrm{b}}{ }^{\star}
$$




$$
\begin{aligned}
e^{\star} & =\left[\left(\psi_{y y}{ }^{\star}-\psi_{x x^{\star}}\right)^{2}+4 \psi_{x y} y^{\star 2}\right]^{\frac{1}{2}}, \\
\tau^{\star} & =\left[\phi_{x y}{ }^{\star 2}+\frac{1}{4}\left(\phi_{y y}{ }^{\star}-\phi_{x x^{\star}}\right)^{2}\right]^{\frac{1}{2}} .
\end{aligned}
$$

The volume $V$ may be extended to $y=\infty$, that is

$$
\int_{V} \mathrm{~d} V=\int_{0}^{M} \mathrm{~d} x \int_{\nu h}^{\infty} \mathrm{d} y,
$$

and the trial functions $\phi^{\star}$ and $\psi^{\star}$ are required to satisfy

$$
\left.\begin{array}{ll}
\psi^{\star} \rightarrow 0 & \text { as } y \rightarrow \infty, \\
\psi^{\star}=h & \text { on } y=\nu h,
\end{array}\right\}
$$

and

$$
\begin{aligned}
& \int_{0}^{M}\left[\phi_{y y^{\star}}+\phi_{x x^{\star}}\right] \mathrm{d} x \rightarrow 0 \quad \text { as } y \rightarrow \infty, \\
& \left(\mathrm{I}-\nu^{2} h^{\prime 2}\right) \phi_{x y}{ }^{\star}+\nu h^{\prime}\left(\phi_{y y}{ }^{\star}-\phi_{x x}{ }^{\star}\right)=0 \quad \text { on } y=v h \text {, } \\
& \left.\begin{array}{c}
\phi_{x y}{ }^{\star} \rightarrow-\nu \alpha(x), \quad y \rightarrow \infty, \\
\frac{\mathrm{I}}{M} \int_{0}^{M} \alpha(x) \mathrm{d} x=\mathrm{I} .
\end{array}\right\}
\end{aligned}
$$

Now, because the inequalities $(27)$ and $(28)$ are equalities at the solution, it follows that the precise sliding law for any given bedrock must be of the form

$$
\tau_{\mathrm{b}}=R u_{\mathrm{b}}{ }^{\star_{1} / n},
$$

where

$$
R=\min \left[\frac{\mathrm{I}}{M} \int_{V} e^{\star(n+1) / n} \mathrm{~d} V\right]
$$

Because of the nature of the asymptotic approach, $R$ is independent of $\sigma$; furthermore the rather elaborate choice of scaling ensures that $R=O(\mathrm{I})$ (and remains so as $v \rightarrow 0$ ); in other words, we have extracted the important functional dependence of the sliding law on $\sigma$ and $\nu$. From Equations (29) and (37), we can see that the sliding law may be written as

$$
u_{\mathrm{b}}=\frac{\sigma}{\nu^{n+1}}\left(\frac{\tau_{\mathrm{b}}}{R}\right)^{n}
$$

and $R=O(\mathrm{I})$ as $\sigma, v \rightarrow 0$. Of course the power-law form of Equation (39) has been deduced by other authors (e.g. Weertman, 1957) in the case where regelation is neglected. What is important here is the explicit form of how the relative magnitude of the basal velocity is dependent on the parameters $\sigma$ and $\nu$ : since $R$ is a measure of the scaled roughness, and is dependent on the form of $h$, it is convenient to refer to these other parameters as the asperity $(\sigma)$, and the corrugation $(\nu)$, which gives some description of what they mean. We see that the size of $u_{\mathrm{b}}$ (as a proportion of the typical flow velocity) is determined by the value of $\sigma / \nu^{n+\mathrm{I}}$, and is therefore strongly dependent on the corrugation $\nu$ (since $n+\mathrm{I} \approx 4$ ). Now we require $u_{\mathrm{b}} \gg O(\sigma)$ for the above analysis to be valid, and hence also $\nu^{n+1} \ll \mathrm{I}$, whence formally $\nu \ll \mathrm{I}$. This justifies from a mathematical point of view the use (by Nye, 1969 and others) of a weakly corrugated bedrock $\nu \ll \mathrm{I}$, even though $\nu$ may be not very small. For example, with $\sigma \approx \mathrm{IO}^{-2}$, $\sigma / \nu^{n+1} \approx \mathrm{I}$ if $\nu \approx \frac{1}{3}$ (sliding is comparable to shearing), whereas if $\nu \approx \mathrm{I}, \sigma / \nu^{n+1} \approx \sigma$, and sliding is negligible (even though the preceding analysis is invalid). 
On the other hand, if $\nu \approx \frac{1}{5}$, then $\sigma / \nu^{n+1} \approx 6$, which simply indicates that sliding is the dominant mechanism of motion. In short, any observed (steady-state, non-surging) sliding velocity may be explained on the basis of Equation (39), simply by adjusting the corrugation accordingly.

We have not yet mentioned specific estimates for the roughness $R$, which clearly are of some importance if the order of magnitude arguments presented here are to be correct. Bounds on $R$ are liable to be rather wild (though certainly of numerical order one) unless certain assumptions are made on the bedrock topography. For example, if we consider the sinusoidal bedrock $y=\nu \cos x$, then it is found (Fowler, unpublished) that as $\nu \rightarrow 0$

$$
\text { I. } 39<R<\mathrm{r} .53 \text {. }
$$

To conclude this section, we mention some further effects which could rationally be included in the preceding analysis. Since the water-film thickness is governed by Equation (12), it is by no means obvious that $\Sigma>0$ for all $x$; in other words, the film may well vanish down-stream of bedrock protuberances, and in this case there must exist the cold patches predicted by Robin (1976). On the short term, these patches may be frozen to the rock-or at least they must offer a frictional resistance to the ice motion. In the first case, the motion must be of stick-slip (stictional) type, since the sticking will be periodically released by a jerking forward of the ice; in either case, an appropriate modification to the ice-flow model would be to apply an averaged non-zero stress $\tau_{\mathrm{S}}$ at the bedrock. The effect may be shown to be additive, and one obtains (to $O(v)$ ),

$$
\tau_{\mathrm{b}}=R u_{\mathrm{b}} \star_{\mathrm{I}} / n+\tau_{\mathrm{s}} .
$$

The magnitude of such a $\tau_{\mathrm{S}}$ is of course a question of some debate. Finally we note that Equation (4I) may also model an applied traction due to frictional rubbing against the bedrock (Morland, r $976[\mathrm{~b}]$ ), and could even be used to model the effect of regelation over length scales $\lambda_{*} \ll[x]$, if this were known with any certainty.

\section{Temperature dependence of the sliding Law}

In previous work, it has always been taken for granted that the sliding law of Equation (Io) is valid only for temperate ice, and that cold ice is frozen to the bedrock, so that the no-slip condition $u=0$ is valid there. Now, although this is undoubtedly true for most subfreezing temperatures, it is reasonably obvious from a physical point of view that this state of affairs cannot be precisely accurate for temperatures which are below, but very close to, the melting point. At such temperatures we expect regelation to be partially effective in maintaining a lubrication film at the bedrock, so that a certain degree of basal sliding can take place, but less than the full temperate value.

The cold patches described by Robin (1976) necessarily exist when such "sub-temperate" sliding takes place, and it follows that the motion must be of stick-slip type (as described earlier): in view of the important fact (Fowler, 1979) that such sub-temperate basal regions may well occur under a large part of the glacier, it is not really surprising that stick-slip motion of this type has been observed. In such conditions, one would not expect any correlation between the (average) basal velocity and the basal stress (and hence depth) - cf. Hodge (1974).

Let us finally note that detection of such sub-temperate regions is likely to remain semitheoretical: for example, if $\nu \approx \frac{1}{4}$, and the basal stress is $c$. I bar, then we expect typical variations of pressure within the basal ice flow of 4 bar. Even allowing for larger fluctuations, it is reasonable to suppose that the variation of melting temperature at the bedrock due to the variation in pressure is < $<0$ bar $\times 0.0074 \mathrm{deg} / \mathrm{bar} \approx 0 . \mathrm{I} \mathrm{deg}$ : thus we would not expect sub-temperate basal regions to be more than a tenth of degree below the pressure-melting point. The experimental detection of such temperature differences at the glacier bedrock is 
likely to cause considerable difficulty. Although experimental confirmation may be slow in forthcoming, one should not underestimate the apparently minor significance of choosing a continuous temperature-dependent sliding law, rather than the more usually accepted discontinuous one, since as described by Fowler (1979), this alteration has a major effect on the dynamic state of a glacier.

\section{Cavitation: meghanisms and effect}

We lastly consider the effects of cavitation on the sliding law. The existence of cavities has been confirmed experimentally, and they have been studied by Lliboutry (I968), who first grasped their importance to the sliding law. Most authors assume cavities form by means of the pressure in the water film becoming equal to the triple-point pressure where ice, water, and water vapour can co-exist. At such points the ice separates from the bedrock, since the pressure is then not sufficiently great to keep it in contact with the rock. This mechanism is directly analogous to ordinary cavitation in fluid flow (Batchelor, 1967). On examination of the lubrication equation (12) describing the dimensionless thickness $\Sigma(x)$ of the film, we can see that an alternative mechanism of cavity formation appears to be available, and is that $p^{\prime}(x)=0$ when $\int_{x_{0}}^{x} V_{\mathbf{M}}(x) \mathrm{d} x \neq 0$. There seems to be no obvious reason why this condition should not generally hold, and in this case one would expect both cold patches and cavities to occur naturally at the bedrock. Such cavities would seem to be the natural equivalent of the vortices formed in boundary-layer separation (Batchelor, 1967) when the skin friction (analogous to the pressure gradient here) becomes zero. A theoretical consideration of this mechanism has not been attempted, but would be of some interest in view of the rather stringent condition on the bedrock corrugation $\nu$ for cavitation to occur by the more usual mechanism (Morland, I 976[a]).

The proper mathematical treatment of cavities formed in the usual way is obtained by applying on the unknown cavity roof the extra boundary condition that the water pressure there is a given constant (the triple-point pressure). (For cavitation by $p^{\prime}=0$, it is not entirely obvious what the appropriate formulation should be.) This makes the ice-flow problem more difficult, as it becomes a (partially) free-boundary problem, and in the general case no techniques are yet available to cope with it.

If, however, we make the (drastic) assumptions that the flow is Newtonian $(n=\mathrm{I})$, and the corrugation is asymptotically small $(\nu \ll \mathrm{I})$, then the explicit form of the sliding law with cavitation is available to first order. The equation of slow Newtonian two-dimensional motion for the stream function $\psi$ is the biharmonic equation

$$
\nabla^{4} \psi=0,
$$

and the appropriate boundary conditions for the flow over a rough periodic bedrock $y=\nu h_{\mathrm{R}}$ in the asymptotic limit $\nu \rightarrow$ o may be written

$$
\begin{gathered}
\left.\begin{array}{rl}
\psi & \rightarrow 0 \quad \text { as } y \\
\psi & =-u_{\mathrm{b}} h_{\mathrm{R}}(x) \\
\psi_{y y}-\psi_{x x} & =0
\end{array}\right\} \quad \text { on } y=0,
\end{gathered}
$$
where we have for convenience subtracted off the uniform stream at infinity. The solution of
Equation (43) is given by

$$
\psi=\operatorname{Re}\left[z^{*} f(z)+g(z)\right]
$$


where $f$ and $g$ are analytic functions of the complex variable $z=x+\mathbf{i} y$, and $z^{*}$ is the complex conjugate of $z$. The determination of the functions $f$ and $g$ is carried out by analysing the boundary conditions. When cavitation is present and $\nu \ll \mathrm{I}$, we find that to leading order in $v$ this analysis is formulated as a mixed Hilbert problem (ordinary problems of this type are described for example by Carrier and others (1966): the novelty in the present case consists of the mixture of two different kinds of Hilbert problem because of the partially free boundary). Its solution is given elsewhere (Fowler, unpublished), and the resulting sliding law is shown below for the particular choice of a sinusoidal bed $y=\nu \cos x$. We see that the scaled (as in Equation (29)) dimensionless basal velocity is equal to the basal stress $\tau_{\mathbf{b}}$ up to a certain critical stress $\tau_{\mathrm{c}}$, at which point cavitation sets in, and the sliding velocity increases without limit at the same basal stress.

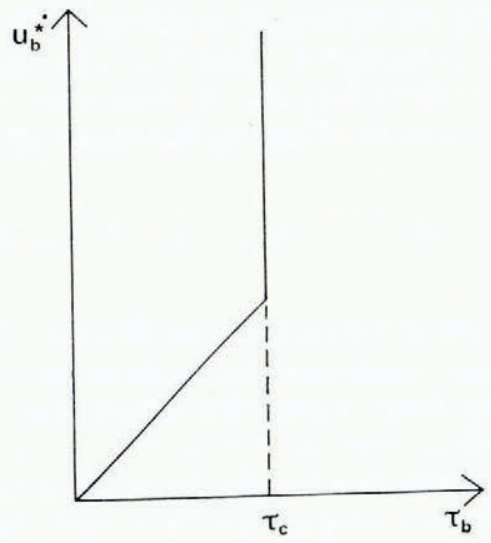

Fig. 2. Cavitational sliding law.

This striking behaviour is similar to that discussed by Lliboutry (1968), who proposed that the sliding law $F\left(\tau_{\mathrm{b}}\right)$ might well become multivalued when cavitation was introduced. Although the present result is not conclusive, it also indicates that such multivaluedness may well occur, especially in view of the unknown effects of including higher-order terms in $v$ and of considering the non-linearity of the flow law. If this is found to be true, it will be expected to have a major effect on the dynamics of glacier flow, since Nye's (I960) kinematic wave equation will then have a multivalued flux term (cf. Fowler, I979).

\section{REFERENGES}

Batchelor, G. K. 1967. An introduction to fluid mechanics. Cambridge, Cambridge University Press.

Carol, H. The formation of roches moutonnées. Fournal of Glaciology, Vol. I, No. 2, p. 57-59.

Carrier, G. F., and others. 1966. Functions of a complex variable, by G. F. Carrier, M. Krook, and C. E. Pearson. New York, McGraw-Hill Book Co., Inc.

Fowler, A. C. 1979. The use of a rational model in the mathematical analysis of a polythermal glacier. Fournal of Glaciology, Vol. 24, No. 90.

Fowler, A. C. Unpublished. Glacier dynamics. [D.Phil. thesis, University of Oxford, 1977.]

Fowler, A. C., and Larson, D. A. 1978 . On the flow of polythermal glaciers. I: model and preliminary analysis. Proceedings of the Royal Society of London, Ser. A, Vol. 363 , No. 1713 , p. $217-42$.

Hodge, S. M. 1974. Variations in the sliding of a temperate glacier. Fournal of Glaciology, Vol. 13, No. 69,

p. 349-69.
Johnson, M. W., jr. 1960. Some variational theorems for non-Newtonian flow. Physics of Fluids, Vol. 3, No. 6, p. $87 \mathrm{I}-78$. 
Johnson, M. W., jr. 196r. On variational principles for non-Newtonian fluids. Transactions of the Society of

Kamb, W. B. 1970. Sliding motion of glaciers: theory and observation. Reviews of Geophysics and Space Physics,
Vol. 8, No. 4, p. $673-728$.

Lliboutry, Glaciology, Vol. 7, No. 49, p. 2 I -58.

Morland, L. W. 1976[a]. Glacier sliding in temperate glaciers. Fournal of Glaciology, Vol. i6, No. 74, p. I5I-58. p. $447-62$.

Morland, L. W.

No. 77 , p. $46_{3}-77$

Glacier sliding down an inclined wavy bed with friction. Journal of Glaciology, Vol. i 7, Society of London, Ser. A, Vol. 256, No. 1287 , p. $559-84$. Nye, J. F. 1969. A calculation on the sliding 128 , p. 559-84.

Proceedings of the Royal Society of Londiding of ice over a wavy surface using a Newtonian viscous approximation. Nye, J. F. I 970 . Glacier sliding without, Ser. A, Vol. 3 i r, No. 1 506, p. 445-67.

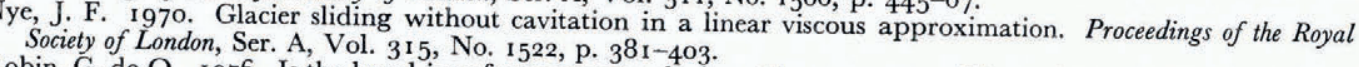

Robin, G. de Q. 1976 . Is the basal ice of a temperate glacier Vol. 16 , No. 74, p. $183-96$.

Van Dyke, M. D. 1975. Perturbation methods in fuid mechanics. Second edition. Stanford California, Parabolic Press.

Weertman, J. 1957. On the sliding of glaciers. Fournal of Glaciology, Vol. 3, No. 21, p. 33-38. 